\title{
К ВОПРОСУ РАССМОТРЕНИЯ ИННОВАЦИЙ В ВЫСШЕМ ОБРАЗОВАНИИ КАК ФАКТОРА КОНКУРЕНТНОГО ПРЕИМУЩЕСТВА СУБЪЕКТОВ РОССИЙСКОЙ ФЕДЕРАЦИИ
}

\author{
(c) 2020 Николаева Елена Анатольевна \\ кандидат социологических наук, доцент, кафедра иностранных языков № 3 \\ Российский экономический университет им. Г.В. Плеханова, Россия, Москва \\ Email:yoltash82@mail.ru \\ (c) 2020 Глухова Елена Владимировна \\ кандидат географических наук, старший научный сотрудник, \\ кафедра рационального природопользования \\ Московский государственный университет им. М.В. Ломоносова, Россия, Москва \\ E-mail: evglukhova@gmail.com \\ (C) 2020 Кузнецова Юлия Андреевна \\ кандидат экономических наук, доцент, кафедра иностранных языков № 3 \\ Российский экономический университет им. Г.В. Плеханова, Россия, Москва \\ Email: yulia_success@mail.ru \\ (c) 2020 Супрунов Семен Евгеньевич \\ старший преподаватель, кафедра иностранных языков № 3 \\ Российский экономический университет им. Г.В. Плеханова, Россия, Москва \\ Email:kafmkk@mail.ru
}

В статье авторов рассматриваются инновации в высшем образовании как фактор конкурентного преимущества субъектов Российской Федерации. Объектом исследования выступило высшее образование в Российской Федерации, а предметом - инновации, как фактор конкурентного преимущества субъектов Российской Федерации. Теоретическое и методологическое значение исследования заключены в развитии теории и методологии инноватики и конкурентных преимуществ. Практическое значение исследования заключается в возможности усиления конкурентных преимуществ субъектов Российской Федерации за счет использования и усиления их инновационного потенциала, формализованного, в том числе инновационными мероприятиями в сфере высшего образования.

Ключевые слова: Вопрос, рассмотрение, инновации, высшее образование, фактор, конкурентное преимущество, субъект, Российская Федерация.

В условиях современной действительности процесс анализа практически любого субъекта невозможен без рассмотрения его конкурентных преимуществ [1, с. 67], относительно аналогичных или схожих с ним субъектов на определенном рынке. Не исключением здесь являются и субъекты Российской Федерации [9], которых по состоянию на начало 2020 года насчитывается порядка 86 единиц, включая республики (22 единицы), края (9 единиц), области (46 единиц) города федерального значения (3 единицы), автономная область (1 единица), автономные округа (4 единицы) и иные территории. Так по данным аналитического агентства «Эксперт РА» ключевыми пространствами в рамках которых функционирует множество конкурентных преимуществ субъектов Российской Федерации [5] на начало 2020 года являются [8]: финансы, инновации, демография, нормативно-правовые конструкции и экология (рис. 1).

Из рисунка 1 можно ясно увидеть, что пространство инноваций [2, с. 13] уверенно занимает вторую строчку (в совокупности $22,45 \%$ или чуть менее одной четверти из 100\%), исходя из распределения уровня значимости совокупности ключевых пространств на начало 2020 года.

В свою очередь каждое из ключевых пространств включает в себя интеграл локальных объектов (факторов), также обладающих уровнями значимости в рамках отдельно взятого опре- 


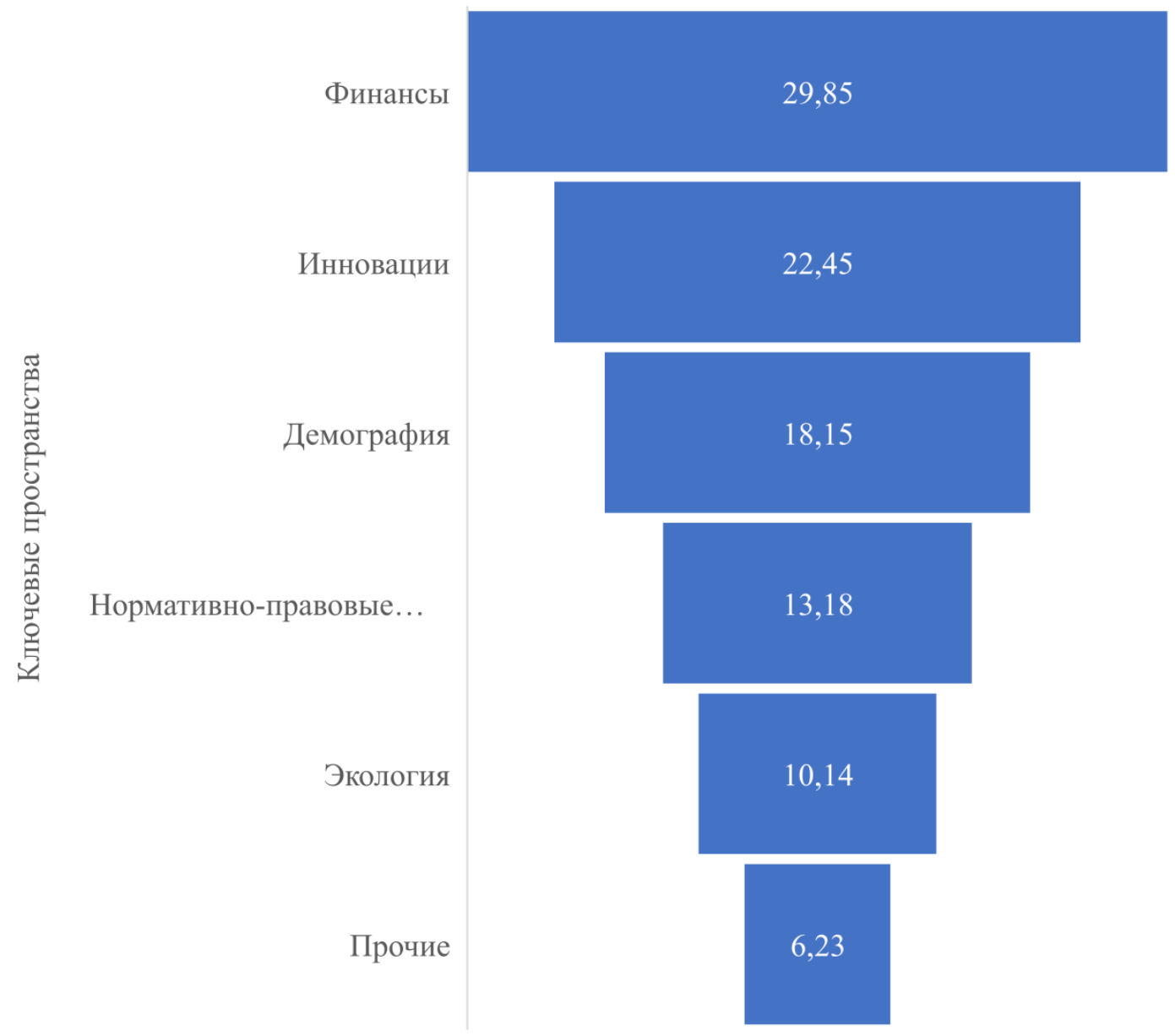

Puc. 1. Ключевые пространства функционирования субъектов Российской Федерации по состоянию на начало 2020 года, распределенные по уровню значимости,\% (суммарная величина значимости 100\%)

деленного пространства.

Так, например, один из наиболее значимых факторов пространства инноваций для субъектов Российской Федерации связан с инновациями, применяемыми в высшем образовании [3, $6,7]$ в конкретном субъекте. Значимость данного фактора оценивается на уровне 3,98\% из 22,45\% (немногим меньше четверти), относящихся к анализируемому пространству (таблица 1).

Дадим некоторые комментарии к таблице 1:

- элементы пространств (от инноваций в промышленной сфере до инноваций в сфере культуры - в совокупности девять единиц) представляют собой конкретные формации закрепления отдельных видов близких по содержанию инноваций и объединения их групп;

- перечень пространств, исходя из многообразия форм и видов инноваций, влияющих на конкурентный статус того или иного субъекта является открытым;
- ранжирование элементов пространств, обозначенных выше, осуществлено на основе использования показателя «уровень значимости элемента», обозначенного в процентном эквиваленте;

- границы изменения обозначенного показателя расположены в интервале от 0\% (минимально возможное значение - определено математическим пределом обозначенной величины) до 22,45\% (максимально возможное значение - определено уровнем значимости ключевого пространства «Инновации»);

- минимальное значение уровня значимости элемента приходится на позицию «Прочие инновации» (значение на анализируемую дату составляет 0,09\% из 22,45\%);

- максимальное значение уровня значимости элемента приходится на позицию «Инновации в промышленной сфере» (значение на анализируемую дату составляет 6,19\% из 22,45\%); 
Таблица 1. Состав пространства инноваций для субъектов Российской Федерации по состоянию на начало 2020 года

\begin{tabular}{|l|c|c|}
\hline \multicolumn{1}{|c|}{ Элемент пространства } & $\begin{array}{c}\text { Уровень значимости } \\
\text { элемента, \% }\end{array}$ & $\begin{array}{c}\text { Рейтинг исследованности } \\
\text { элемента (0-100), ед. }\end{array}$ \\
\hline Инновации в промышленной сфере & 6,19 & 35 \\
\hline Инновации в сфере строительства & 5,45 & 25 \\
\hline Инновации в сфере высшего образования & 3,98 & 10 \\
\hline Инновации в сфере здравоохранения & 2,54 & 5 \\
\hline Инновации в сфере торговли & 1,96 & 4 \\
\hline Инновации в социальной сфере & 0,93 & 2 \\
\hline Инновации в прочих видах образования & 0,78 & 1 \\
\hline Инновации в сфере культуры & 0,53 & 100 \\
\hline Прочие инновации & 0,09 & \\
\hline Сумма & 22,45 & 3 \\
\hline
\end{tabular}

- среднее значение уровня значимости всех обозначенных элементов (сформировано по средней арифметической величине) находится в районе 2,49\% из 22,45\%;

- уровень значимости интересующего нас элемента «Инновации в сфере высшего образования» расположен немногим выше средней границы, что соответствует его существенной значимости в анализируемом рейтинге;

- рейтинг исследованности элементов представляет собой интеграл аналитически обработанных мнений экспертов (метод групповой экспертной оценки) в области инноваций на начало 2020 года;

- значения девяти обозначенных элементов рейтинга изменяются от 0 (минимально возможное значение) до 100 единиц (максимально возможное значение);

- значения рейтинга по обозначенным элементам могут характеризовать уровень теоретической и практической изученности воздействия определённого элемента на уровень конкурентных преимуществ субъектов Российской Федерации;

- шаг изменения рейтинга элементов, исходя из критериев существенности и целесообразности построения рядов данных в экономической сфере, определен в 1 единицу;

- минимальное значение рейтинга исследованности элементов приходится на позицию «Прочие инновации» (значение на анализируемую дату составляет 1 ед. из 100 ед.);

- максимальное значение рейтинга исследованности элементов приходится на позицию «Инновации в промышленной сфере» (значение на анализируемую дату составляет 35 ед. из 100 ед.);
- среднее значение рейтинга исследованности всех обозначенных элементов (сформировано по средней арифметической величине) составляет 11,11 ед. из 100 ед.;

- рейтинг исследованности интересующего нас элемента «Инновации в сфере высшего образования» расположен немногим ниже средней границы, что соответствует его недостаточной изученности как в теоретической, так и практической плоскости.

В целях данной публикации был проведен анализ элемента «Инновации в сфере высшего образования» [4, с. 32] как фактора конкурентного преимущества субъектов Российской Федерации. Результаты данного анализа на начало 2020 года отражены на рисунке 2.

Данные рисунка 2 свидетельствуют о следующем:

- большая часть субъектов Российской Федерации (чуть менее 70\%, согласно представленным данным) используют или планируют использовать инновации в сфере высшего образования в качестве фактора конкурентного преимущества;

- порядка четверти субъектов Российской Федерации (25,12\%, согласно представленным данным) на анализируемую дату, ввиду тех или иных значимых для них причин, точно не определились со своим выбором;

- менее 30\% субъектов Российской Федерации, согласно представленным данным, не планируют использовать анализируемый фактор вообще.

Таким образом, можно сделать вывод, что в Российской Федерации существуют значимые перспективы относительно использования ин- 
— Доля позиции, \%

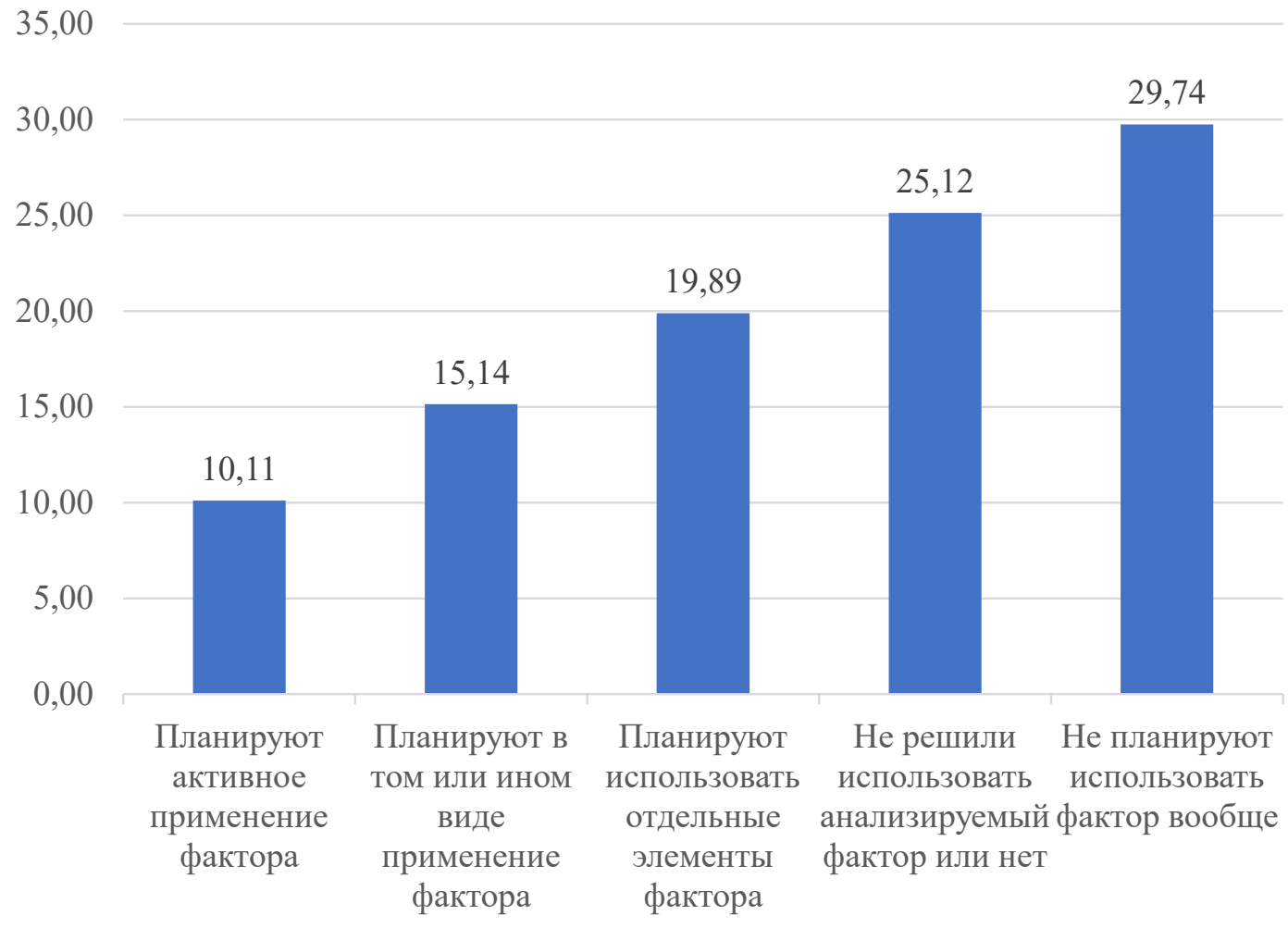

Позиция субъекта

Puc. 2. Результаты анализа элемента «Инновации в сфере высшего образования» как фактора конкурентного преимущества субъектов Российской Федерации на начало 2020 года,\%

новаций в высшем образовании с целью формирования конкурентных преимуществ субъектов.

Для активизации данных перспектив, по мнению авторов, целесообразно использовать существующий инновационный потенциал отдельно взятого субъекта, усиливая при этом целенаправленное воздействие на каждый значимый для него элемент в определенный период времени.

Содержание конкретных действий, формализующих использование существующего инновационного потенциала субъекта эффективнее всего инициировать с передовых и наиболее перспективных с точки зрения коммерческой составляющей локаций.

\section{Библиографический список}

1. Барсуков И. Е., Касимов Л.Б. Факторы конкурентоспособности российских регионов / И.Е. Барсуков, Л.Б. Касимов // Экономика и управление: проблемы, решения - Москва: Изд-во: «Издательский дом «Научная библиотека», 2018. - № 1.-С. 65-68.

2. Бобомуродов П. У. Зависимость инновационной деятельности от уровня образования и подготовки кадров / П.У. Бобомуродов // Образование и наука в России и за рубежом - М.: Изд-во: Московский двор (Москва), 2018. - № 1.- С. 7-13.

3. Васецкая Н.О., Глухов В.В. Оценка ресурсов научно-инновационного потенциала высшей школы России / Н.О. Васецкая, В.В. Глухов // Управление экономическими системами: электронный научный журнал Кисловодск: Изд-во: «Кисловодский институт экономики и права», 2018.- № 3.- С. 1.

4. Кот В. В., Зотова Т. А., Устинов Д. Ю. Институциональные инновации и адаптивное поведение в российской сфере образования / В.В. Кот, Т.А. Зотова, Д.Ю. Устинов // Управленец - Екатеринбург: Изд-во: «Уральский государственный экономический университет», 2018. - № 1.- С. 31-37. 
5. Николаева Е.А., Григорьева И.В. и др. К аспектам влияния оценки эффективности деятельности профессорскопреподавательского состава высшего учебного заведения на укрепление экономической безопасности Российской Федерации / Е.А. Николаева, И.В. Григорьева, И.С. Казимирова, Е.И. Соколова // Экономические науки - Москва: Изд-во: ООО «24-Принт», 2019._- № 3.- С. $62-67$.

6. Плохотникова Г.В., Дальченко Е.А. Приоритетные направления развития конкурентных преимуществ региона (на примере ростовской области) / Г.В. Плохотникова, Е.А. Дальченко // Экономика и предпринимательство - Москва: Изд-во: «Редакция журнала «Экономика и предпринимательство», 2018.- № 1.С. 335-337.

7. Филлипова Л.Г. Проблемы создания малых инновационных предприятий в вузах / Л.Г. Филлипова // Вестник марийского государственного университета - Йошкар-Ола: Изд-во: «Марийский государственный университет», 2018. - № 1.- С. 102-108.

8. Компания «Эксперт РА» [Электронный ресурс]: аналитические материалы - Официальный сайт компании «Эксперт РА», 2020.- Режим доступа: www.raexpert.ru

9. омпания «Делойт Туш Томацу Лимитед» [Электронный ресурс]: аналитические материалы - Официальный сайт компании «Делойт Туш Томацу Лимитед», 2020.- Режим доступа: www.deloitte.com 